\section{A 1 inte}

\section{POSTURAL ALBUMINURIA.}

By Sir WilliaM H. BROADBENT, M.D.,' F.R.S., Physician-in-Ordinary to the King and to the Prince of Wales ; Consulting Physician to St. Mary's Hospital.

Functionac albuminuria, which was the subject of three important papers read before the Medical Society by the President, Dr. Rose Bradford, and Dr. West, and of an interesting debate, is a question which has occupied my attention for many years, and as time did not permit of my taking part in the discussion, I hope I may be allowed to make a few observations now.

The first point which comes out is the necessity for greater precision in the definition of what we mean by functional albuminuria. Albuminuria can never be physiological ; the term "functional," though admissible in the sense given to it by Dr. Pavy as a contra-distinction to structural, is vague; the albuminuria of the apparently healthy, the designation accepted by Dr. Rose Bradford, is still more unsatisfactory. To begin with, many of the subjects of intermittent albuminuria are not in apparent health; they faint in church or at drill, as pointed out by Dr. Armstrong and Dr. Clement Dukes, and as a descriptive term it includes structural disease of various kinds and continuous, as well as intermittent or occasional,presence of albumen in the urine. It can only serve as a starting-poirt for discrimination and classification. Without entering upon this point, which occupied much of all three of the original papers, it may be said definitely that there is an affection which may be called postural albuminuria. We can eliminate early nephritis and nephritis in process of recovery, early stages of contracted granular kidney, unsuspected heart disease, albuminuria from fever, from overfeeding or indigestion, gout or oxaluria, or from adventitious discharges from different parts of the genito-urinary tract. There is left a group of cases in which the characteristic feature is albuminuria on rising from bed in the morning, usually passing off in the course of the day. These cases are exceedingly common, especially in boys and young men working up for examination, and, applied to them, the designation albuminuria of adolescence is perfectly appropriate, but the name postural albuminuria is no doubt better, as open to no uncertainty. The albumen is not due to food; it does not appear if the patient remains in bed to breakfast or after meals later in the day; it cannot, as was clearly shown by Dr. Rose Bradford, be toxaemic; it disappears quickly on lying down. It is obviously in relation with the erect posture after a night's rest in bed, and scarcely less obviously with imperfect cardiovascular adjustment to the changed hydrostatic conditions. Albuminuria from excessive exertion is also circulatory, the cardio-vascular capacity for adjustment having been overpassed. It does not seem to me that any antecedent affection of the kidneys by febrile disease need be postulated.

The amount of albumen is usually small, but it may be very considerable. It is important that this form of albuminuria should be recognized, since the treatment required is the exact reverse of the milk diet and protection from exposure to cold and fatigue, which would be suitable in renal disease ; and the debate will have been of signal service if it should lead to the adoption of the term postural.

The antecedent which in my experience has been most common is a neurotic family history, and the condition invariably existing in the patients themselves has been cardio-vascular instability. The pulse varies greatly in frequency and tension, often while under examination, certainly at different periods of the day, and is unduly influenced by changes of position, such as lying down or standing up. A distinctly high-tension pulse, not very uncommon in childhood and early youth, would take the patient out of the category of postural albuminuria, and would warrant suspicion of actual rènal disease or of juvenile gout.

The action of the heart affords further evidence of the instability of the circulatory system. Both Dr. Pavy and Dr. Armstrong spoke of the violent cardiac impulse. According to my experience it is the impulse of the right ventricle which is forcible, the apex beat being weak. Contrast between a weak apex beat and leftiventricle sounds and the powerful right ventricle impulse and loud sounds has seemed to me to be constant in these cases. Another observation of like significance is that the second sound is reduplicated when the patient lies down.

The prognosis is favourable. I have never known true postural albuminuria to resist treatment or to develop intoactual renal disease. Usually all the treatment required is good simple food, fresh air, and vigorous exercise. There is no need to forbid school games, except perhaps house runs and long paper-chases. Tonics such as iron, arsenic strychnine, and quinine will be useful in many of the cases. Constipation should be corrected by aloetic or other aperient. of the tonic class. On the morning after a mild pil. hydrarg., c. colocynth, et hyoscyamo the albumen may be absent. even when habitually abundant. This should be borne in mind when a candidate for one of the public gervices has to. undergo the medical examination.

If these cases are treated for renal disease, put on milk diet, protected from cold, and forbidden to take exereise, they will probably go from bad to worse, and I have met with several instances of confirmed nervous valetudinarianism apparently attributable to this error in early life.

\section{A SUMMARY OF

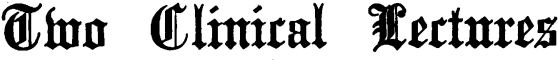 ON}

\section{EMPYEMA AND BRONCHIECTASIS.} Delivered in the Edinburgh Royal Infirmary. By ALEX. JAMES, M.D., F.R.C.P.EDIN. Physician to the Infirmary.

WE have seen how a large bronchiectatic cavity, when incised and drained through the chest wall, tends to produce a pleural cavity. The fibrosed lung around the bronchiectatic cavity, being allowed to contract by the establishment of drainage, separates itself from the parietal pleura to which it has been previously bound by adhesions, and so tends to produce a pleural cavity which much resembles an empyema. The diagrams show how this occurs; they also show two practical points which should always be borne in mind in dealing with such cases. The first is that extensive resection of ribs is as necessary for the healing of a large bronchiectatic cavity as it is for an old-standing empyema. The second is that, if this extensive rib resection is not performed, we must, as time goes on, experience increasing difficulty in introducing the drainage tube into the lung cavity through the pleural opening.
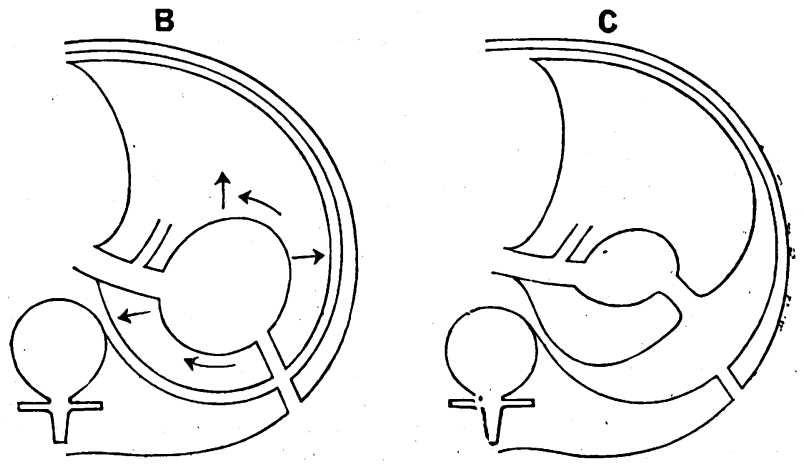

The diagrams represent how a large bronchieetatic cavity $\mathbf{B}$ will tend to contract and form a pleural cavity $C$, as the result of the estabof its distending forces.

Let me here further make a slight digression to demonstrate how these same mechanical conditions account for the difficulty which we experience in the healing of phthisical empyemas. I have a skiagraph of one such case, which was lately in my ward, and in which, months after the operation, could be seen a long probe passed through the wall opening, which easily reached the apex of the lung above the clavicle! In this case the original empyema cavity had been a relatively small one containing only about ro oz. or 12 oz. of pus-but it had been sufficient to start progtessive cicatricial contraction of the lung apex, and so_to reparate it from the posterior wall of the chesti. 
But next we also have seen that an inflammatory effusion into the pleural cavity can produce a bronchiectatic cavity. In its simplest form this occurs when a sero-fibrinous effusion has lasted too long. In this case the portion of lung corresponding to the effusion has its air cells obliterated, and its tissues transformed into what is practically fibrous tissue. As the pleuritic fluid gradually becomes absorbed the space left in the thorax must be filled up. In part this is done by drawing in of the chest wall, by drawing up of the diaphragm, by drawing over the heart and mediastinum, and by producing the neighbourhood which are still capable of being inflated. But in other part-and this is the important matter-this space is filled up by drawing outward the bronchial walls, and thus producing a bronchiectasis.

When the pleuritic effusion is purulent and, still more, when it is fetid as well, this bronchiectatic production process is much more active and more serious. In such cases we have in the first place the same factor acting as in serofibrinous effusion, namely, the lung tissue with its obliterated air cells, which with the removal of the pus cannot be reinfated; but, secondly, a purulent, and still more a fetid purulent, effusion tends to erode its way through the lung tissue into a bronchial tube. This, although it is Nature's way of bringing about recovery, and though it is often fortunately successiul enough; is often unfortunately not successful because it is insufficient. A certain amount of the pus gets away by expectoration, and the patient feels better; but soon the opening through the lung closes, and the purulent fluid collects again, to come away after it has regathered in sufficient quantity to burst through. In this way the patient goes on for weeks or months expectorating pus, and suffers irom all the bad results of insufficient drainage.

But we have to note a still more unfortunate occurrence. The pus, and specially so if it is fetid pus, sets up irritative and destructive, perhaps gangrenous, changes in the lung tissue in its course through it to the bronchi ; it irritates also to a very great degree the bronchial tissues themselves. In this way portions of lung tissue are destroyed and bronchial walls over large areas are weakened, so that if eventually the empyema pus be got rid of and the original empyema cavity closes, the patient is left with a bronchiectasis. That empyema, and specially fetid empyema, is frequently a cause of bronchiectatic cavities is certain, and I now wish to describe cases in which this process was either taking place or had already occurred. I shall not waste time by describing instances of empyemata, or of bronchiectatic cavities which were easily recognized, and easily got at and drained. I shall describe only those in which the indications were not absolutely clear, and the treatment by drainage presented some little difficulty.

The first case is one in which a fetid empyema still existed. and was in process of setting up basal lung destruction and bronchorrhoea.

CASE I.

J. P., aged 46, maltister in a brewery, was admitted to the Royal Infirmary, November 2 nd, 1903 , complaining of pain in the chest, cough, and fetid spit, and stating that he had been ill about seven weeks. His family history is very good, at home and at work his surroundings are favourable enough, except that at the brewery lie has probably been in the habit of taking too much alcohol. He has had no previous illuesses nor accidents.

History of Present Illness.-He developed a cough about seven weeks ago, but this for two weeks did not trouble him much. He then experienced a pain in the side, which necessitated his laying up, and from his account seems to have been accompanied with some fever. This condition continued till about a fortnight before his admission, when the pain became much worse, and with the cough he noticed sudden marked increase in the amount of spit, and that it smelt very foul. His medical adviser, suspecting an empyema, had explored the chest at the right base, and had apparently struck a purulent collection. Subsequently, however, the chest had been again explored at two places and no pus found. The feverish condition and fetid spit continuing he was sent into Ward $3 \mathrm{I}$.

On admission he was found to be a man of good development, though somewhat poor in muscularity and anaemic looking. His temperature varied from $97^{\circ} \mathrm{F}$. to $100^{\circ} \mathrm{F}$., 'his pulse was about 120 , and his respiratory embarrassment was such that he could not lie down in bed, his respirations being about 40 per minute. Nothing abnormal was found facemexion with his alimentary, circulatory and urinary systems. His

Areatipgs, in twenty-four hour varied from 12 to $14 \mathrm{oz}$. On examination of his chest we found an limpaired percussion note on the right side posteti-

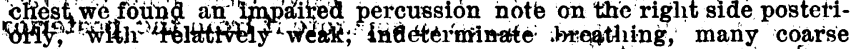
crepitations, and rhonchi over this area. The chepstations could be traced over the upper lobe on this side, and also over the lower lobe on the left side.

Here then was a case in which we believed there was a small fetid empyema of the right lower lobe. It had burst through into the bronch there and was setting up a fetid bronchitis. Some of the pus was being aspirated into the bronchi of the left side, and was setting up irritation there also. We first tried in his case the effects of nourishing diet and antiseptic inhalations, in the hope that with this help Nature might do all that was required. In this, however, Nature did not slow signs of succeeding after about a week's trial. I therefore determined to get a largish portion of the posterior part of the eighth rib (about 3 in.) excised, feeling sure that if no empyema was discovered at the operation I should subsequently be able thoroughly to explore the whole lung base through this opening and strike pus, either in some unsuspected empyema cavity or in some somewhat dilated bronchial tube situated in the disintegrating lung tissue. The advantage which claim for this plan is that the numerous punctures which from time to tim may be required in such cases can be done without hurting the patient, and therefore with a completeness which would be practically impossible if each individual exploratory puncture had to be made through the skin in the ordinary way. As I anticipated, this case turned out a com paratively simple one. Dr. Macgillivray kindly did the resection for me, and at the operation he was able, by pushing an exploring needle through the thickened pleura in a direction upwards and towards the spine, to strike a small fetid empyema cavity. The opening was then enlarged and about an ounce of fetid pus evacuated. It was drained in the usual way, and the patient is rapidly recovering.

This case shows very clearly how a very small fetid empyema can set up a very copious fetid spit. As has been stated, the cavity hardly contained an ounce of pus, whilst the patient was expectorating at least $120 \mathrm{oz}$. in the twentyfour hours. The explanation of this is that the bulk of the expectoration is the result of a fetid bronchitis or bronchorrhoea.

The next case is one in which the empyema had healed itself, but had set up fetid bronchiectasis.

CASE II.

A. II., aged 27 , belonged to the mercantile marine, was admitted to the infirmary on April gth, rgor, complaining of cough and copious fetid spit. His family history was very good, as also were his surroundings. There is no doubt, llowever, that he tended rather to exceed as regards alcohol. He had had the ordinary diseases of childhood, and no other illness, except typhoid fever some years before when in China.

History of Present Illness.-His present illness began some ten weeks before his admission. He had cough and chest pain in the left side, and he seems also to have been feverish for some weeks. He had noticed little clots of blood in the spit, and somewhat suddenly the spit became much more copious and fetid. This cough and fetid spit have continued, sometimes better, sometimes worse. He also felt himself getting weaker and thin, and so he applied for admission to the infirmary,

State on Admission.-He appeared a fairly well nourished and developed man. His height was $5 \mathrm{ft}$. $5 \frac{1}{2}$ in., weight I 1 st. He says he was much heavier and stronger, but his muscles have gone down lately. His temperature varied from $97^{\circ}$ to $99.5^{\circ}$, his pulse from 80 to $9 \circ$; his respirations were about 8 per minute. He was able to move about fairly well. tions were about 18 per minute. He was able to move about fairly well. His digestive, circulatory, integumentary, lrinary, and nervous
systems showed nothing abnormal. His blood showed a slight leucocytosis.

Respiratory System.-Patient has now no chest pain, except after coughing, when he feels a soreness in the throat and left side. His cough is troublesome, and his spit, which is very fetid and offensive, amounts to about $20 \mathrm{oz}$. in the 24 hours. The spit shows numerous organisms, and some diplococci. On examination of the chest there was found at the left base an area of dullness the upper limit of which was curved and reached its maximum just about the line of the scapula, was curved and reached its maximum just about the line of the scapula,
where it reached 3 in. above the normal limit. Over this area the breath sounds were feeble and crepitations were easily made out.

Progress.-Believing that this was an empyema which Nature might cure, and, what was perhaps more important, the patient declining any operative interference more serious than one simple exploratory puncsure, which discovered no pus, we treated him in the ordinary way witl rest, good diet, fresh air, and antiseptic inhalations. He improved considerably, and on April $24_{\text {th }}$ the amount of spit had diminished to about $4 \mathrm{oz}$. in the 24 hours. It was still fetid, though much less so than formerly. Thinking he was better he requested to be discharged, and of course this request was granted.

Second Admission.-He returned on September ${ }_{3}$ rd, feeling weaker and with the cough and fetid expectoration more pronounced than ever, his temperature varying from $97^{\circ}$ to ror ${ }^{\circ}$, and his pulse from 76 to ro4. On examination of his chest we found that the area of percussion dullness, weak breath sounds, and crepitation was much the same as before. We determined on thorough exploration, and the following are the notes of his case.

Operation.- On October 9 th, the patient being put under chloroform Dr. Macgillivray incised over the dull area and resected about 3 in. of the eighth rib. The pleura was found thickened; the wound was packed.

October r.th. Dr. James tried to strike the pus by means of an exploring needle, but was nat successful. Further unsuccessful at tempts, were made, on the \& 4 th, Ioth, 23rd, and 27 th, the peedle, how- 
ever, on all occasions being felt to pass through firm condensed tissue.

October 2 th. Dr. James, in exploring, came on pus. It was found upwands towards the root of the lung, at a distance of about 3 in. from the pleura. The opening was enlarged by a probe-pointed forceps, and a drainage tube about 7 in. long, with only one side opening near the point, was inserted.

November rith. The purulent collection is draining thoroughly. There is practically no cough or spit.

November 22nd. The patient left for home with orders to have the drainage tube looked after by his doctor. The drainage tube has been shortened to about $4 \mathrm{in}$., and some difficulty is experienced in introducing it at times. He has practically no cough or spit, and feels quite well.

The next record of him is in the following June the note being that he had been very well, but that one day he had coughed up some "stringy stuff," and that for three days after he had coughed up some fetid pus, and passed it through the tube. Since then he had been well. Lastly, on December 4 th, spit, and fetor of breath had all gone, that the tube, after having been gradually shortened, had been discontinued, and that the chest wound had healed. Examination at the left base revealed percussion impairment with weak breath sounds, but no crepitation.

In this case there had probably been several bronchiectatic sacculi, only one of which was properly drained. This drainage, however, and the fact that by the rib resection the lung has been allowed to fall in, had practically cured the condition.

\section{Case III.}

The next case was one of fetid empyema, which had produced bronchiectasis and lung induration, and also a sinus through an interspace.

C. K., aged 53, a traveller, was admitted to the Royal Infirmary, August 27 th, r 1903 , complaining of pain in the right side and cough with copious, at times fetid, spit. His family history was fairly good, and his surroundings at home and at work were quite satisfactory. He acknowledged to have taken formerly a good deal of alcohol. He has had practically no previous illnesses.

History of Present Illness. - About six months ago he caught a cold and was feverish, with pain in the right side and cough, his doctor telling him that he had pleurisy. After some weeks he recovered somewhat, and was moving about, and one day he had a severe fit of coughing, and he was moving about, and, one day he had a severe fit of coughing, and he able taste and smell. This condition has persisted till now in spite of able taste and smell. This condition has persisted till now in spite of
all treatment. For some weeks he says he would notice some improvement as regards cough and expectoration, and then for some weeks it would be worse again. At times there is blood in the spit. He has lost nearly 3 st. in weight since the commencement of his. illness, and fecling that no treatment was doing him any good, he came to the Royal Infirmary.

State on Admission. - He was found to be of rather poor muscularity, his height $5 \mathrm{ft}$. 5 in., and his weight $8 \mathrm{st} .4 \frac{1}{2} \mathrm{lb}$. His temperature varied from $97^{\circ}$ to $99.5^{\circ}$, his pulse was usually about 80 per minute and respirations 24 per minute. His digestive, circulatory, urinary, integumentary, and nervous systems were all normal. Examination of his blood showed a leucocyte count of 21,200

Respiratory System.-He has a severe, loose cough, with a large quantity of sputum, sometimes amounting to $20 \mathrm{oz}$. in the 24 hours. It is muancourulen bacilli. At the present the fetor is but slight. Examination of the bacilli. At the present the fetor is but slight. Examination of the
chest shows deficient movement on the right side all over, with a somewhat impaired percussion note posteriorly, becoming dull at the base of the lung. In the right interscapular region there is some pain and tenderness; and on palpation there and down the vertebral of the scapula, some bulging with crackling can be felt, when the patien coughs. On auscultation, the breath-sounds were very faintly heard over the right side, becoming specially faint at the base posteriorly. crepitation can be heard all over the side, especially also at the Crepitation can
base posteriorly.

base posteriorly.
Operation.-Believing that this was the case in which an empyema of the right base had burst into a bronchial tube, and had set up bronchiectasis, with fibroid changes at the base of the lung, and believing that my best chance of draining it would be by getting at it from below, I got $\mathrm{Mr}$. Caird to remove for me about 2 in. of the seventh rib posteriorly. When this was being dome a sinus was found in the fascia close to the ohest wall, leading up to a point opposite the spine of the scapula
where the bulging or coughing had been noticed. A long tube was put where the bulging or coughing had been noticed. A long tube was put
in this sinus, and the wound was packed. Some improvement followed from this, as a good deal of discharge occurred from the sinus, but on my return from my holidays in the beginning of October I determined to explore more thoroughly. Needles passed into the lung from the lower opening had revealed that the whole lung base was indurated ; in fact, it felt as if the needles were passing through cartilage. In a straight line inwards, about 3 in. from the pleura, a purulent collection was struck, and this communication having been enlarged, a drainage tube 5 in. long was introduced.

Progress.-From this time the patient's condition showed marked improvement. - With free drainage along the two tubes, the expectoration soon ceased. By the end of October the upper tube had been discon tinued, and he is now (November $23 \mathrm{rd}$ ) an out-patient, coming up every day or two to get the tube cleaned and replaeed. The tube is now shortened to about 3 in.

In this case there had been, I believe, a fetid empzema, which had burst into the bronchi and possibly also, aided by violent coughing, through the fourth interspace in the interscapular region. By the time he came to the infirmary it had itself disappeared, leaving however a bronchiectasis, an extremely indurated lung base, and a sinus through the chest wall posteriorly. The patient's condition is one which still requires great care, but we may anticipate for him a fair recovery.

It will be evident that with those cases of empyema which have gone on to bronchiectasis, some will be easy of treatment, and others difficult. It is also evident that the difficult ones will be those in which the condition is one of multiple sacculation of bronchi, rather than one of one or two large sacculations. Of such I propose to give one instance out of several in which I have been unsuccessful.

It is evident further that if an empyema occur out of its usual position, more especially if it occur at or near the lung apex, so that when it perforates the lung it can drain in a downward direction, and therefore less incompletely than when it is in its usual situation, its recognition will be more than usually difficult.

The following is a case in point, one in which multiple sacculations of the bronchi existed, and in which efforts to drain were unsuccessful. This was one of the first cases of the kind which I endeavoured to treat in this way.

CAse IV.

H. P., a little girl of 9 , was brought to me at the infirmary in September, r889.

History of Illnes8. - She had been well until about two years previously, when, after exposure to cold, she had "inflammation" in the right side. The nature of this inflammation could not clearly be ascertained, but she had had pain in the side, cough, fever, and sweatings. After some two months, during which time she was mostly in bed, she suddenly coughed up about a teacupful of fetid purulent matter. She seemed to have improved somewhat after this, but the cough and expectoration of fetid matter, though in smaller quantity continued, and she had remained weak and feverish, and was manifestly ill.

State on Admission.-Dullness on percussion was noted, and cavernous breathing and resonating crepitation were heard over the lower half of the right lung, and some harsh breathing with crepitation at the base of the left.

Operation. - In this case I resected portions of two ribs, and on same six or eight occasions afterwards explored from the exposed pleura. Although on one or two occasions I seemed to strike pus, I never could establish a proper drainage. On three occasions, into an opening made by a probe-pointed forceps, a drainage tube was introduced, and left in in

no avail. spit persisting, the child died some six months afterwards. At the necropsy, the larger bronchi at the base of the right lung were found much dilated, and the surrounding lung tissue in a state of fibrosis. The pleura all over the lower lobe was adherent, except at a spot laterally, where about an ounce of yellow serous fluid was found encapsuled. At the left base there existed, but to a very much less marked extent. a similar condition of lung and bronchi.

CASE V.-Fetid Empyema Bursting into the Lung at an"Unusual Position not Recognized.

A. N., aged 49, a cabman, was admitted to the Royal Infirmary March Ixth, I900, complaining of cough, with profuse fetid expectoration and odour of breath. His family history was excellent. As a cabman he has taken a good deal of alcohol, and his home surroundings were good.

History of Present Illness. - Until November, 1898 , he had been perfectly strong and well. At that date, as the result of an exposure, he caught a cold, and was ill in bed with pain in the right side and cough After two weeks of this, during. a severe paroxysm of cough and pain, he suddenly expectorated a considerable quantity of foulsmelling spit. After this he seems to have improved considerably, the cough and spit gradually diminished, and in 2 few weeks he was able to return to work. During the summer of r8g, however, he began to cough again. The spit. was not so copious or bad smelling, but, as time went on, got. gradually worse. In February, rgoo, he was so bad that he had to take to bed. He again had a cough, with an expectoration more copious. and more fetid than before, and at times showing a little blood. H also became feverish and weak, and was troubled with copious perspirations. It was noticed that on some days there would be very little ex pectoration, whilst on others it would be very copious. The cough was apt to occur in paroxysms, and to cause great cyanosis, and these paroxysms, with the chest pain which accompanied them, weakened him very much. Finding himself getting rapidly weaker, he came to the Royal Infirmary.

State on Admission.-Although not extremely emaciated, patient appeared very feeble and weak. The face was rather cyanosed, and very slight movement induced severe paroxysms of coughing, so that thorough examination of his organs could not fitly be made. His temperature variod from of 0 is of fever. His pulse varied from 90 to 130 , and was very feeble. His 
cough was very troublesome, the slightest change of position bringing on a severe paraxysm, with copious fetid expectoration. On examination of the chest the left side was found normal to percussion, whilst on the right side some impairment was met with all over the upper part, and dullness was found over the lower part, especially laterally, where the dull note extended as high as the level of the fifth rib. Auscultation, which was extremely difficult owing to the very feeble condition of the patient and the paroxysms of cough, revealed rhonchi and crepitations over both sides of the chest and very much enfeebled ibreath sounds over the right base posteriorly. The other organs appeared fairly healthy, except that the urine contained a small quantity of albumen.

Progress.-In this case I believed that I had to deal with a bronchiectasis at the base of the right lung, the result most probably of a fetid empyema which had burst into the bronchial tube. I felt that the only possible way of doing good in the case was to drain, and I therefore on several occasions, made exploratory punctures to locate the cavity or cavities. Distinctly to my surprise, however, I never could strike pus, nor could I feel that the exploring needle passed through dense tissue. $\mathrm{I}$ was content, therefore, to limit my treatment to antiseptic inhalations, and cardiac and general stimulants. The patient got rapidly worse, the cough and fetid expectoration continued, some days more, some days less. Paresis of the right arm was noticed, and pericarditis supervened, death occurring on April i ith.

Necropsy.-April 12th. External appearances: Body somewhat - emaciated, general pallor of surface, slight rigidity in lower limbs only. Thorax: Pericardium showed a recent purulent inflammation. Sac contained about half a pint of turbid fluid. The parietal layer was somewhat thickened and covered with fibrinous exudation. The left pleural sac contained about $6 \mathrm{oz}$. of turbid fluid; no adhesions. The right pleural sac showed a very peculiar condition. Over the upper lobe of the lung anteriorly the pulmonary pleura showed dense chronic thickening ( $\frac{1}{8}$ in.) and was firmly adherent to the thoracic wall. When this was perforated an empyema cavity was exposed containing over I $5 \mathrm{oz}$. of fetid brownish pus. This cavity was confined to the anterior portion of the upper lobe of the lung by dense fibrous adhesions, but -eloser investigation showed that the pus had burrowed, both into the chest wall in front and into the lung beiow. As regards the chest wall, it had burrowed through the first and second right intercostal spaces, and ha,l caused gangrenous changes in the muscular tissues there. As regards the lung, it had burrowed through the fbrous adhesions into the anterior portion of the lower lobe.

Right lung: On section this showed extensive collapse. The pleura all round was much thickened, and the lobes were all adherent. In the lower lobe was found a cavity of about the size of a walnut, with soft gangrenous walls, and into this cavity opened three or four bronchi of about $\frac{1}{4}$ in. in diameter, with greatly thickened walls. The entire right lung was much collapsed, so that the liver had risen high into the thoracic cavity. The other organs showed nothing specially noteworthy.

This was a case in which there had been a fetid empyema bursting into the lung, and the fact that the purulent expectoration varied much in amount was due probably to the very imperfect communication between the empyema cavity and the lung tissue. The fact that the empyema cavity was not diagnosed was probably due to its being at the times of examination comparatively empty. The dullness and feeble breathing at the base of the right lung were accounted for by the great collapse and high position of the diaphragm. The slight paresis of the right arm was a condition not at all uncommon in empyema.

\section{THREE CASES OF ABSCESS OF THE LUNG.* By D. J. WILLIAMS, F.R.C.S.Eng., Llanelly.}

THE surgical treatment of suppuration within the thorax has been marked by slower progress than that of allied conditions within the abdominal cavity. Successful if primitive operations on lung abscesses are recorded in medical literature from the time of Hippocrates down to the latter half of the last century, but operative interference in these cases was not recognized as a justifiable proceeding until Lister's antiseptic methods were fully appreciated.

The cases I have to report are-first, one of tuberculous abcess diagnosed as an empyema ; secondly, one of abscess following fibrinous pneumonia, on which no operation was performed; and thirdly, a case of septic embolism and abscess which recovered after operation.

CASE 1.-A. D., aged I4, a pale anaemic girl, gave the following history: About six months ago she had measles, followed by bronchitis and pneumonia on the right side, from which she had not completely recovered. Her father had died of phthisis a year before.

State on Examination.-Movement was impaired over the right side and slight flattening over the left apex. The heart's apex beat was in the left nipple line. There was complete dullness on the right side from * Read at the Tenby meeting of the Bouth-West Wales Division of the South Wales and Monmouthshire Branch of the British Medical Associa- he level of the fourth rib in front and seventh behind, downwards and continuous with that of the liver which projected two fingerbreadths below the costal margin. Vocal fremitus and resonance were absent over the same area. The breath sounds were weak over the left apex, but no adventitious sounds were noted on either side. An exploring needle being introduced above the sixth rib some thick pus vised.

Operation.-On May 8 th, $189 \mathrm{r}$, the patient being anaesthetised, a por tion of the - On May 8 th, $189 \mathrm{r}$, the patient being anaesthetlsed, a por two pints of a slightly opalescent fluid escaped, totally different in two pints of a slightly opalescent fluid escaped, totally different in
character from that withdrawn by the exploring needle. The pulmonary pleura seemed fairly glistening, but on introducing the finger it was found adherent to the costal pleura above. On exploring again above the sixth rib thick pus was again withdrawn. The wound was closed, carefully sutured and sealed with collodion. A second ineision was made over the sixth rib and about an inch of it removed. A sinus forceps was then pushed in by the side of the exploring needle, the cavity freely opened, and about ro to $12 \mathrm{Oz}$. of thick pus evacuated. Some iodoform was introduced, a large drainage tube inserted, and the wound dressed. There was no communication with the bronchus.

Progres8.- The little patient soon improved in health, appetite improved, and when seen three months later she had gained ro lb. in pret tuberculosis of the left lung.

CaSE II.-W. G., aged 26, returned home ill on November 25 th, 1899 and I saw him on the following morning, when he gave the following history : He was quite well up to a month previously, when he had in fluenza, but did not give up his work-that of an engineer. He had bad cough, had rusty expectoration. and pain in the left side. He was allowed to go to his office daily until his return home.

State on Examination.-His left thorax was absolutely dull from apex to base. The heart's apex beat could scarcely be made out, but cardiac dullness extended well beyond the sternum to the right, and all the symptoms of fluid in the left pleural cavity were noted. An exploratory aspiration gave clear fibrinous serum. His temperature was ror ${ }^{\circ}$., pulse Ir $^{2}$, respirations $3^{2}$, and he looked exceedingly pale and ill.

Progress.-Counter-irritation and general treatment resulted, after a week's trial, in no improvement, and it was decided on December ${ }_{3}$ rd to aspirate, and four pints of fluid was withdrawn. Examination of the chest immediately after gave physical signs of consolidation and a guarded prognosis was given. The dry, hacking cough continued, but his general condition was, for a time, improved. Signs of fluid in the pleura cavity reappeared, and on December $22 n d$ it was decided again to aspirate, and a further two pints of fluid were removed. On examination immediately after it was found that the dullness over the lower lobe was increased; the temperature continued high-ro4 in the evening, with morning remissions to ror -and from the general symptoms abscess of the lung was diagnosed. There was no further reaccumulation of fluid in the pleura, but the general condition deteriorated, and the lung symptoms became predominant. I strongly advised operation, and with this view had a consultation on January 27 th. I have this note of his condition on that date: "Temperature 103 $3^{\circ}$, pulse 120 , respirations 30; looks worn out, thin, emaciated, and hectic, percussion note over the but distant, percussion note dull over base, reaching as high as sixth rib in posterior axillary line, breath sounds absent."

RESULT.

The patient's friends adopted the consultant's advice to postpone operation notwithstanding my expressed reluctance. The condition of the patient became gradually worse, and I continued impressing the necessity of operating. Another consultation and another consultant resulted in a further postponement, this time for three days, but before its termination the abscess perforated into the abdomen, probably the colon, and the patient died on March ist, without any operation having been performed.

CASE III.-I was called to see the patient (Mrs. J., aged 33) on June $23 \mathrm{rd}$, 1901, when the following history was elicited. She was taken ill on June 7 th with what was supposed to be influenza; she miscarried at the fifth month, on June inth, and became seriously ill three days later, and the loca! practitioner was called in.

State on Examination.-At my visit on June 23 rd she complained of pain and distension in the abdomen, especially in the pelvic region. There was no cough, but she was constantly sick and the bowels constipated. Her face was flushed, and she complained of great thirst. Her tongue was very dry. Temperature $104^{\circ}$; pulse 120 ; respirations 28. On examination the abdomen was distended and tympanitic, and very tender over the uterus, which could be felt through the abdominal very tender over the uterus, which could be felt through the abdominal
wall and enlarged. Per vaginam the os was patulous, the uterus enwarged and tender and the discharge offensive. The temperature as larged and tender and the discharge offensive. The temperature as
taken in the vagina was $105^{\circ}$. The patient complained of tenderness in taken in the vagina was ro5. The patient complained of tenderness in the left hypoohondrium, and a rounded swelling was felt under the costal pressure, and dull on percussion; this note was continued upwards over the thorax to the level of the fifth rib in the mid-axillary line. There was defective movement of the left side of the thorax, percussion and auscultation normal, breath sounds distinct at the base behind, 